naturally occurring malaria. The mechanism of thrombocytopenia is controversial, but is probably multifactorial. In our patient it might have been due to production of antiplatelet antibody of IgM class. ${ }^{3}$

Evidence of bleeding without DIC is rare. Beale et al $^{3}$ reported one case of subconjunctival haemorrhage among 17 people with thrombocytopenia, three cases of epistaxis, and one of haematuria, but we believe our report to be the first record of cutaneous purpura in malaria. We should like to emphasise that thrombocytopenia and haemorrhage may occur in malaria without DIC. Controversy over the use of heparin in DIC is rife, ${ }^{4}$ but clearly unequivocal evidence of DIC must be obtained before heparin treatment is started.

1 Communicable Diseases Report No 34-35. London, Public Health Laboratory Service, 1976

2 Esan, G J F, Clinics in Haematology, 1975, 4, (1), 247.

${ }^{3}$ Beale, P J, Cormack, J D, and Oldrey, T B N, British Medical fournal, $1972,1,345$

- Reid, H A, Lancet, 1975, 1, 167.

(Accepted 1 February 1977)

Infectious Diseases Unit, West Lane Hospital, Middlesbrough TS5 4EE

SALIL K GHOSH, MB, MRCP, consultant physician

North Ormesby, Middlesbrough

I NICOLSON, MB, CHB, general practitioner

\section{Glibenclamide and syndrome of inappropriate secretion of antidiuretic hormone}

The oral hypoglycaemic drug glibenclamide has been reported to cause a diuresis both in healthy people and in patients with diabetes mellitus.' This effect may be due to antagonism to the action of antidiuretic hormone $(\mathrm{ADH})$. $^{2}$ We have used glibenclamide to treat a patient with the syndrome of inappropriate secretion of $\mathrm{ADH}$ (SIADH) with the following results.

\section{Case report}

A 30-year-old woman with SIADH of unknown aetiology was admitted to the metabolic unit. There was no evidence of intracranial disease, renal disease, chest disease, or neoplasia, and her management had consisted in fluid restriction since the diagnosis was made five years earlier. After a baseline period of three days a 12-hour water deprivation test with measurement of maximum urine osmolality was performed. Next day a four-hour water tolerance test was carried out with a challenge of 1 litre of water, the urine volume and minimum urine osmolality being measured. The patient was then given oral glibenclamide $2.5 \mathrm{mg}$ each morning, the water deprivation and water tolerance tests being repeated on the third and fourth days of treatment, starting two hours after the dose of glibenclamide. The dose was then increased to $5 \mathrm{mg}$ daily and subsequently to $10 \mathrm{mg}$ daily and the procedure repeated. Finally, the investigations were repeated after two days only on $20 \mathrm{mg}$ daily. Plasma osmolality was measured before each water test, and plasma ADH was measured ${ }^{3}$ during the baseline period and before the water tests two hours after giving the $10-\mathrm{mg}$ and $20-\mathrm{mg}$ doses. During the entire study period the daily intake of sodium, potassium, and fluid remained constant. Plasma glucose was monitored throughout the study.

Plasma ADH was raised during the baseline period at $12.3 \mathrm{ng} / 1$ (norma range 4-8 $\mathrm{ng} / \mathrm{l}$ ) and remained raised during the treatment with glibenclamide. In addition there was no significant change in any of the variables measured during treatment compared with the baseline period (figure). In particular, no increase in urine flow was seen, in contrast to previous reports. $^{12}$

\section{Comment}

In this patient glibenclamide did not modify the circulating concentration of $\mathrm{ADH}$ and did not have a diuretic effect. Our findings suggest that the diuretic effect of glibenclamide may not be through antagonism of $\mathrm{ADH}$ or through suppression of $\mathrm{ADH}$ secretion. Alternatively, the $\mathrm{ADH}$ concentrations in this patient may have been
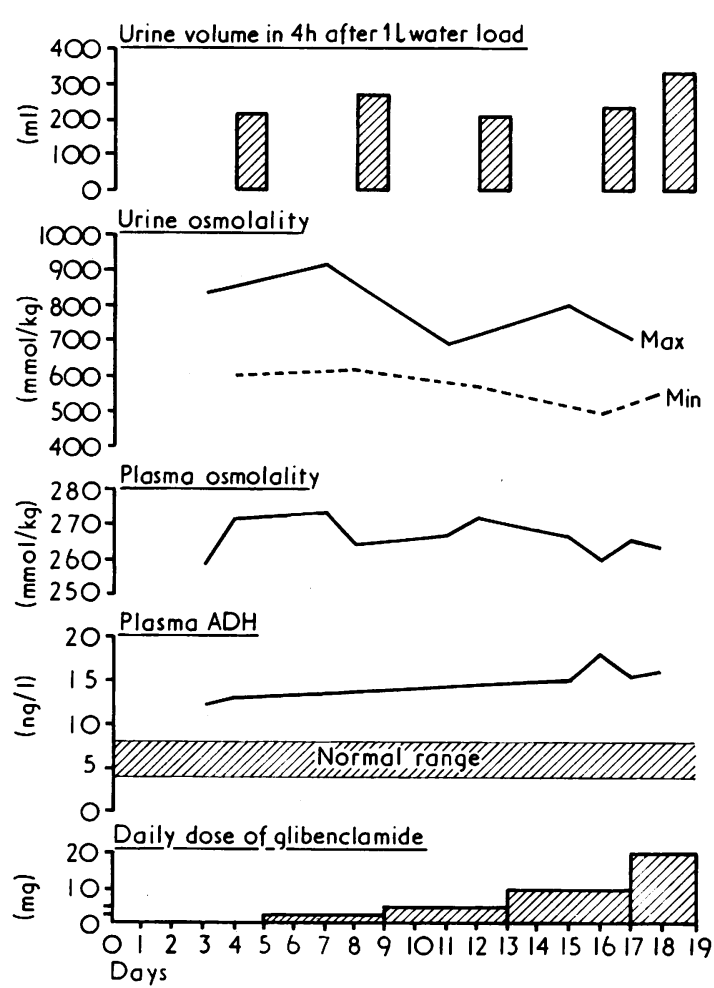

Absence of significant change in variables measured during treatment with glibenclamide.

Conversion: SI to traditional units-Urine and plasma osmolalities: $1 \mathrm{mmol} / \mathrm{kg}=1 \mathrm{mOsm} / \mathrm{kg}$.

too high for antagonism of $\mathrm{ADH}$ and consequent diuresis to be apparent.

${ }^{1}$ Moses, A M, Howanitz, J, and Miller, M, Annals of Internal Medicine, 1973, 78, 541

2 Rado, J P, Szende, L, and Marosi, J, Metabolism, 1974, 23, 1057.

${ }^{3}$ Morton, J J, Padfield, P L, and Forsling, M L, fournal of Endocrinology, $1975,65,411$

(Accepted 27 fanuary 1977)

Metabolic Unit, University Department of Medicine, Western General Hospital, Edinburgh EH4 2XU

$P$ L YAP, MB, CHB, senior house officer

A D B HARROWER, MRCP, senior registrar

N MCD DAVIDSON, MRCP, lecturer

J A STRONG, MD, FRCP, professor of medicine

MRC Blood Pressure Unit, Western Infirmary, Glasgow G11 6NT J J MORTON, PHD, non-clinical scientist

\section{Bronchial carcinoma metastasising to the ischiorectal fossa}

Carcinoma of the bronchus is noted for its tendency to metastasise extensively. Nevertheless, it rarely metastasises to muscle and it has never been reported as spreading to fat. We report a case of carcinoma of bronchus which presented with a secondary deposit in the fat and muscle of the ischiorectal fossa.

\section{Case report}

A 72-year-old man presented with a two-week history of perianal pain exacerbated by the passage of stool. He had been well, specifically denying any weight loss and respiratory symptoms. He was a heavy smoker and had not been on antibiotics preceeding admission. He was afebrile, with a large 